\title{
Políticas Públicas de Inclusão: 0 acesso da pessoa surda ao ensino superior
}

Leila Santos Mesquita'

'Universidade de Pernambuco (UPE), Recife/PE - Brasil

RESUMO - Políticas Públicas de Inclusão: o acesso da pessoa surda ao ensino superior. Este trabalho discute o acesso da pessoa surda ao ensino superior considerando os limites e avanços das políticas públicas educacionais de inclusão. Por meio de questionários com pessoas surdas concluintes do ensino médio de uma escola da rede pública de Pernambuco, destaca-se, como barreiras de acesso ao ensino superior, a falta de reconhecimento da língua de sinais como primeira língua e a dificuldade de apropriação da língua portuguesa por parte das pessoas surdas. Conclui-se, portanto, que a educação bilíngue é uma possibilidade de avanço desse quadro.

Palavras-chave: Políticas de Inclusão. Educação de Surdos. Ensino Superior.

ABSTRACT - Inclusive Public Policies: access of deaf students to higher education. This paper intends to discuss the enrollment of deaf students in higher education, with focus on the limits and progress of recent public policies of access. A questionnaire was used to interview deaf students from a public high school from the state of Pernambuco, Brazil. The study demonstrates that the non-recognition of sign language as first language and the lack of appropriation of Portuguese language by deaf people are barriers to the access of deaf students to higher education. In face of it, bilingual teaching emerges as a way to increase enrollment. Keywords: Inclusive Public Policies. Deaf Education. Higher Education.

Educação \& Realidade, Porto Alegre, v. 43, n. 1, p. 255-273, jan./mar. 2018. 


\section{Introdução}

Este trabalho resultou de uma investigação realizada no âmbito da dissertação de mestrado em educação e discute sobre o acesso das pessoas surdas ao ensino superior no contexto das políticas educacionais de inclusão e de democratização do acesso à universidade.

O percurso histórico das pessoas com deficiência é constituído de várias fases, todas marcadas pelo estigma da exclusão. Esse percurso definiu-se nitidamente por fases como o extermínio, a maldição, o confinamento, a internação, a segregação e outras formas de exclusão (Santiago, 2011). A história educacional das pessoas surdas não foi diferente. Existem relatos que comprovam momentos de avanços e retrocessos.

Apesar do histórico de exclusão, dados estatísticos divulgados pelo Relatório sobre Política Linguística da Educação Bilíngue (Brasil, 2014) mostram que, de acordo com o Censo Escolar do INEP de 2012, o número de alunos surdos na educação básica era, até então, de 74.547. Já aqueles que ingressaram no ensino superior, o Censo de 2011 apresenta um total de 1.572 surdos e de 4.078 considerados deficientes auditivos. Para esclarecer essas duas denominações, o decreto no 5.626 (Brasil, 2005), em seu artigo $2^{\circ}$ traz uma definição para pessoa surda como "aquela que, por ter perda auditiva, compreende e interage com o mundo por meio de experiências visuais, manifestando sua cultura principalmente pelo uso da língua brasileira de sinais - Libras". Quanto à deficiência auditiva, o mesmo artigo apresenta, em parágrafo único, uma definição clínica da surdez. Com isso, podemos inferir que pessoa surda se diferencia de deficiente auditivo por questões linguísticas e culturais.

Diante desse quadro que o Censo traz, objetivamos demonstrar como vem ocorrendo especificamente o acesso da pessoa surda ao ensino superior, considerando os limites e os avanços das políticas educacionais de inclusão.

A pesquisa de campo foi realizada em uma escola de ensino médio da rede pública de Pernambuco. A construção teórica teve como fundamentos os estudos de Quadros e Karnopp (2009), Quadros (2008; 2011), Skliar (2012), Goldfeld (2002) e Góes (2002) quanto à educação e à linguagem dos surdos. Ainda no corpo da fundamentação, temos as políticas educacionais de inclusão, consolidadas em conferências e convenções internacionais, e os direitos linguísticos, referendados na lei $n^{\circ} 10.436$ (Brasil, 2002), decreto no 5.626 (Brasil, 2005) e na lei $n^{\circ} 10.098$ (Brasil, 2000), regulamentada pelo decreto no 5.296 (Brasil, 2004), que preconiza sobre acessibilidade.

Este texto se constitui da descrição sucinta do histórico de educação das pessoas surdas, trazendo uma abordagem das filosofias educacionais que permearam ao longo de cinco séculos. Em seguida, delineia as políticas educacionais de inclusão e as políticas de democratização do acesso ao ensino superior. Na seção seguinte, apresentamos nosso processo metodológico através do diálogo entre os limites e os avanços

$\overline{256}$ Educação \& Realidade, Porto Alegre, v. 43, n. 1, p. 255-273, jan./mar. 2018. 
das políticas educacionais de inclusão e os processos seletivos de acesso ao ensino superior para pessoas surdas.

\title{
Propostas Educacionais e as Políticas Linguísticas para as Pessoas Surdas
}

Os primeiros registros da história da educação das pessoas surdas datam do século XVI, uma vez que, em épocas anteriores, essas pessoas eram excluídas e vistas como seres primitivos e impossíveis de serem educados. Desde então, estudiosos interessados na educação das pessoas surdas desenvolveram diferentes metodologias.

\begin{abstract}
Alguns se baseavam apenas na língua oral, ou seja, a língua auditiva-oral utilizada em seu país, como o francês, o inglês, etc. Outros pesquisaram e defenderam a língua de sinais, que é uma língua espaço-visuo-espacial criada através de gerações pelas comunidades de surdos. Outros ainda criaram códigos visuais, que não se configuram como uma língua, para facilitar a comunicação com seus alunos surdos (Goldfeld, 2002, p. 28).
\end{abstract}

Durante esse percurso histórico, decorreram vários embates entre os estudiosos pela definição da melhor filosofia a ser aplicada na educação das pessoas surdas. Surgem assim, após esse período, três filosofias denominadas por oralismo, comunicação total e bilinguismo.

A filosofia oralista percebe a surdez como uma deficiência. Com isso, visando a integração do surdo na comunidade de ouvintes, tem como objetivo a reabilitação da criança surda rumo à normalização. Dessa forma, foram desenvolvidas várias metodologias de oralização, como verbo-tonal, aural, acupédico, audiofonatória, dentre outras (Goldfeld, 2002, p. 33; p. 34). O oralismo se fortalece a partir do Congresso de Milão ${ }^{1}$, ocorrido no ano de 1880 . Nesse congresso, é definido que a língua oral é o melhor método para o ensino da pessoa surda. Durante anos esse método foi a única forma de educação de surdos.

A filosofia chamada de Comunicação Total, como descreve Goldfeld (2002), apesar de também ter como propósito a aprendizagem da língua oral, leva em consideração o desenvolvimento dos aspectos cognitivos, emocionais e sociais e tem como foco principal o processo comunicativo. Com isso, as atividades desenvolvidas na Comunicação Total (CT) resultaram no uso de vários recursos associados visando à comunicação. Assim, o enfoque que no oralismo era voltado para a reabilitação, na CT passa a ser na pessoa, que, com a marca da surdez, apresenta uma diferença, concebendo-se dessa forma em uma questão de ordem social (Goes, 2002, p. 41).

As diversas possibilidades utilizadas pela comunicação total proporcionaram o surgimento de uma proposta que consiste no uso da língua de sinais e da língua portuguesa simultaneamente, denominada de bimodalismo. Essa proposta se constituiu na prática de utilizar a língua de sinais como suporte para o aprendizado da língua oral escrita, configurando o que se chamou de português sinalizado.

Educação \& Realidade, Porto Alegre, v. 43, n. 1, p. 255-273, jan./mar. 2018. 
Ao apresentar aspectos da comunicação total, Quadros (2008), com base em Ciccone (1990 apud Quadros, 2008), infere que a mesma pode ser tomada como base filosófica para o bilinguismo. $\mathrm{O}$ autor também afirma que a língua de sinais e a língua oral são autênticas, no sentido de que são equivalentes em níveis de qualidade, referindo-se à importância das línguas envolvidas no processo.

Dessa forma, as constatações acima apontam o surgimento de uma nova proposta - o bilinguismo -, que se fortalece com o impulso de pesquisas linguísticas, como as de Stokoe (1960 apud Quadros, 2008), Karnopp (2009), nos Estados Unidos, e Brito (1995), no Brasil, sobre as línguas de sinais. Essas pesquisas consolidaram a importância da língua de sinais para a comunidade surda, levando ao reconhecimento legal dessa língua por meio da implementação de políticas públicas linguísticas que asseguram uma educação bilíngue para as pessoas surdas (Quadros; Campelo, 2010).

No entanto, Quadros (2011) diz que o bilinguismo na educação do surdo não tem as mesmas características de outros contextos bilíngues, como o ensino de duas línguas orais. Na educação dos surdos, esse processo é atípico, porque envolve línguas de modalidades diferentes -uma é oral auditiva e a outra é espaço visual -, constituindo, assim, um processo desafiador para estudantes surdos e educadores.

\section{O Reconhecimento Legal da Libras e a Proposta Bilíngue}

Apesar de a comunicação gesto visual existir por toda história da humanidade e de ter sido sistematizada em diversos períodos durante a educação de surdos, somente no século XX passa a ser estudada e compreendida como uma língua natural e, portanto, pertencente a um grupo que a adquire de forma natural, possivelmente, se confirmando como primeira língua para esse público, servindo aos propósitos linguísticos inerentes a uma língua.

As pesquisadoras Brito (1995), Felipe (2001) e Quadros e Karnopp (2009) destacam-se aqui no Brasil por dedicarem-se aos estudos sobre a língua de sinais e sobre as questões pertinentes à educação dos surdos. Sobre as línguas de sinais, Quadros e Karnopp (2009, p. 30) afirmam que:

As línguas de sinais são consideradas línguas naturais e, consequentemente, compartilham uma série de características que lhes atribui caráter específico e as distingue dos demais sistemas de comunicação [...] As línguas de sinais são, portanto, consideradas pela linguística como línguas naturais ou como um sistema linguístico legítimo e não como um problema do surdo ou como uma patologia da linguagem. Stokoe, em 1960, percebeu e comprovou que a língua dos sinais atendia a todos os critérios linguísticos de uma língua genuína, no léxico, na sintaxe e na capacidade de gerar uma quantidade infinita de sentenças. 
No entanto, antes que a língua de sinais brasileira chegasse a ter seu reconhecimento legal, ela passou por vários processos diretamente associados à história da educação dos surdos. O primeiro indício de sistematização do uso da língua de sinais na educação dos surdos no Brasil inicia com a chegada de E. Huet, professor surdo francês, que traz a língua de sinais francesa e adequa ao ensino de surdos brasileiros. Assim, sob a influência da língua de sinais francesa, a língua de sinais utilizada pelos surdos brasileiros vai se constituindo na língua brasileira de sinais. Em seguida, a criação do Instituto Nacional de Educação dos Surdos (INES), fundado a partir da escola particular criada pelo professor, torna-se referência na educação de surdos (Quadros; Campelo, 2010).

Depois desse período, as associações de surdos que se espalham por todo o Brasil têm papel fundamental para a afirmação da língua de sinais e a constituição da identidade política e cidadã das pessoas surdas. É a partir desse contexto, materializado pelos encontros e movimentos dos surdos que se configuram as políticas linguísticas do reconhecimento cultural e social dos utentes dessa língua.

Assim, apoiadas pelos movimentos, são implementadas as legislações sobre a língua de sinais. A lei no 10.436 (Brasil, 2002), no art. 1º, reconhece como meio legal de comunicação e expressão a Língua Brasileira de Sinais (Libras) e outros recursos de expressão a ela associados. O decreto $n^{\circ} 5.626$ (Brasil, 2005) regulamentou a lei 10.436 Brasil, 2002), orientando um "planejamento linguístico" que consiste em medidas de implantação obrigatória, e em prazo determinado, da língua de sinais em cursos de formação de professores e nos cursos de fonoaudiologia. Também regulamenta a formação de instrutores e intérpretes/tradutores de Libras, com o objetivo de atender a demanda dos cursos de licenciatura e dos demais níveis de ensino, visto que existe também, previsto na legislação, um direcionamento para a educação bilíngue.

Embora o bilinguismo se apresente historicamente no Brasil desde os anos de 1990, de acordo com Quadros (2008), após as políticas linguísticas, o debate sobre o bilinguismo se reveste de outra perspectiva. No campo teórico, intensificam-se as discussões sobre os processos de aquisição e aprendizagem da língua de sinais como língua natural e a língua portuguesa como segunda língua na educação dos surdos. A participação de pesquisadores surdos e outros estudiosos que investigam a surdez no âmbito da socioantropologia aquece a discussão.

Nesse sentido, Skliar (2012) chama atenção para a educação bilíngue e para o risco da permanência de projetos assimétricos de poderes e saberes, como demonstrado nas filosofias anteriores. Ou seja, a manutenção do domínio de uma língua sobre a outra - a língua portuguesa utilizada por professores ouvintes predominante na educação de surdos - pode fortalecer a relação de poder da língua oral sobre a língua de sinais.

Entretanto, segundo Skliar (2012, p. 8), as novas concepções sobre surdez e reconhecimento da língua de sinais não vêm garantindo o sucesso escolar das pessoas surdas, mesmo com a abordagem bilíngue e bicultural.

Educação \& Realidade, Porto Alegre, v. 43, n. 1, p. 255-273, jan./mar. 2018. 
As limitações na organização de projetos políticos, de cidadania, dos direitos linguísticos, e as dificuldades no processo de reorganização e de reconstrução pedagógicas, ainda sugerem a existência de uma problemática educacional não revelada totalmente. Em outras palavras, a questão não está no quanto os projetos políticos se distanciam do modelo clínico, mas no quanto realmente se aproximam de um olhar antropológico e cultural.

Nesse sentido é que buscamos discutir a contribuição de Skliar (2012) sobre o enfoque que dá à educação dos surdos na perspectiva da visão socioantropológica. Esse autor propõe pensar a questão da surdez epistemologicamente, considerando analisar as relações entre conhecimento e poder a partir de uma dimensão política. Assim, menciona algumas representações afirmando que "a surdez constitui uma diferença a ser politicamente reconhecida; a surdez é uma experiência visual; a surdez é uma identidade múltipla ou multifacetada e, finalmente, a surdez está localizada dentro do discurso sobre a deficiência" (Skliar, 2012, p. 11).

As representações citadas acima, excluindo o discurso sobre deficiência, estão relacionadas com a vertente que defende uma posição epistemologicamente política da surdez, negando o foco na deficiência e na normalização registrada em toda história do surdo.

\section{Políticas Educacionais de Inclusão e o Acesso ao Ensino Superior}

A base dos direitos iguais e da educação acessível para todos está escrita na Declaração Universal dos Direitos Humanos (Brasil, 1948). A partir desse documento, os caminhos percorridos na educação de pessoas com deficiência rumam em direção ao novo paradigma, fundamentado na concepção dos direitos humanos, conjugando igualdade e diferença como valores indissociáveis.

O movimento de inclusão surge em meados da década de 1980, nos Estados Unidos, com ações de pais e pessoas com deficiências, que lutam, por meio da política de integração proposta em vários países, contra a ideia da condição de segregação que a educação especial imprimiu às pessoas com deficiência, através da política de integração proposta em vários países.

Dentre os eventos mais importantes e determinantes para a constituição das políticas de inclusão, destacam-se a Conferência Mundial sobre Educação para Todos (Jontiem, 1990), a Convenção Interamericana para Todas as Formas de Discriminação contra a Pessoa Portadora de Deficiência (Guatemala, 2001) e um destaque para Declaração de Salamanca (1994), que encerrou os resultados da Conferência Mundial de Educação Especial; esta mais voltada para a educação das pessoas com deficiência (Carneiro, 2007).

Mais recentemente, em 2006, a ONU aprova a convenção sobre os direitos das pessoas com deficiência, definindo-a como o resultado da 
interação entre as pessoas com deficiência e as barreiras, nas atitudes e nos ambientes, que impedem a sua plena participação na sociedade em igualdade de oportunidades com as demais pessoas. O Brasil, a partir dessa convenção, assume o compromisso de assegurar um sistema educacional inclusivo em todos os níveis (Brasil, 2010).

Neste mesmo ano é lançado o Plano Nacional de Educação em Direitos Humanos (PNEDH). O Estado brasileiro tem como princípio a afirmação dos direitos humanos como universais indivisíveis e interdependentes e, para sua efetivação, todas as políticas públicas devem considerá-los na perspectiva da construção de uma sociedade baseada na promoção da igualdade de oportunidades e da equidade, no respeito à diversidade e na consolidação de uma cultura democrática e cidadã (Brasil, 2007a).

O PNEDH, com relação à educação superior, tem como princípio garantir a democratização da informação, o acesso por parte de grupos sociais vulneráveis ou excluídos e o compromisso cívico-ético, com a implementação de políticas públicas voltadas para as necessidades básicas desses segmentos.

Paralelamente a esse contexto histórico em prol da inclusão, delimitam-se os acontecimentos sociais políticos e econômicos em âmbito internacional que influenciam nos direcionamentos políticos e educacionais do Estado Brasileiro.

\section{Políticas de Democratização do Acesso ao Ensino Superior nos Governos de FHC e Lula}

Para discutirmos sobre a democratização do acesso ao ensino superior, fizemos um recorte nos períodos dos governos compreendidos entre Fernando Henrique Cardoso (FHC, 1995-2002) e Luiz Inácio Lula da Silva (Lula, 2003-2011) e as políticas educacionais desenvolvidas nesse período.

Traçando uma abordagem geral sobre as propostas educacionais do governo FHC, destaca-se a implantação de um conjunto de reformas como os Parâmetros Curriculares Nacionais (PCN), o Sistema Nacional de Avaliação da Educação Básica (SAEB), o Exame Nacional de Cursos (ENC), o Fundo de Manutenção e o Desenvolvimento do Ensino Fundamental (FUNDEF).

Ainda na era FHC, no âmbito da educação especial, podemos apresentar o documento Política Nacional de Educação Especial na perspectiva da integração instrucional, publicado em 1994, que traz em suas diretrizes a possibilidade dos alunos com deficiência participarem de atividades programadas para sua inserção aos grupos ou às classes dos ditos normais (Brasil, 2010, p.12). Temos nesse período também a Lei de Diretrizes e Bases da Educação Nacional (Brasil, 1996a), que já contempla as premissas da educação inclusiva quando trata em seus artigos no 205 e 206, respectivamente da educação como direitos de todos e da igualdade de condições para o acesso e a permanência na escola.

Educação \& Realidade, Porto Alegre, v. 43, n. 1, p. 255-273, jan./mar. 2018. 
A partir da Conferência Mundial de Educação Especial em Salamanca, em 1994, que culminou com a elaboração do documento intitulado Declaração de Salamanca sobre os princípios, política e práticas em educação especial, são definidas, no Brasil, como país signatário, as políticas públicas de educação inclusiva. Então, em 2001, é publicada a resolução CNE/CEB no 2 (Brasil, 2001), art. no 2, que determina que os institutos de ensino devam matricular todos os alunos, assegurando uma educação de qualidade para todos.

Segundo Cunha (2003), a política de reforma no ensino superior foi pensada nos anos de 1980, cuja versão foi elaborada pelo Grupo Executivo Para a Reformulação da Educação Superior (GERES). Essas propostas atravessaram os governos de José Sarney (1985-1990), Fernando Collor (1990-1992) e Itamar Franco (1992-1994). No entanto, as propostas germinadas neste período tomam força apenas no governo FHC, que tanto encarnava os preceitos norteadores da concepção neoliberal, quanto acatava as orientações das instituições multilaterais mais fortemente representados pelo Banco Mundial e pela UNESCO. Essas instituições são responsáveis pelas diretrizes que estabelecem regras, reformas educacionais e políticas dos países membros e partícipes destas organizações, sempre sob a égide dos ideais hegemônicos da economia.

Ainda no que diz respeito à democratização do acesso ao ensino superior, o então ministro da educação Paulo Renato, do governo FHC, avança com a proposta de uma nova modalidade de ingresso ao ensino superior com sistema de seriação para alunos provenientes da rede pública. A Universidade de Brasília (UnB) foi a primeira, em 1998, a aprovar alunos através desse sistema. Em seguida surge o Exame Nacional do Ensino Médio (Enem) como meio de avaliar a educação básica. A partir de então, a iniciativa privada se utiliza desse processo de seleção. Hoje o Enem é o principal sistema de avaliação para o ingresso ao ensino superior também nas universidades públicas.

No momento posterior, a nação brasileira passa a ser dirigida pelo governo de Luiz Inácio Lula da Silva, que, apesar de dar continuidade à política calcada no pensamento neoliberal, amplia a reforma atendendo determinada demanda da sociedade com programas sociais. No entanto, apesar disso, caminha em direção contrária ao governo anterior, ao aumentar a participação do Estado, principalmente no que diz respeito às políticas sociais (Souza Junior, 2011, p. 41).

Nesse período, o ministério da educação teve a direção de três ministros e, de acordo com a análise de Dalila Oliveira (2011, p. 327), os dois primeiros não conseguiram estabelecer uma agenda que se contrapusesse à anterior. A autora complementa dizendo que, no geral, manteve-se a "fragmentação e descontinuidade da década passada", marcando principalmente os primeiros anos desse governo. Porém, na gestão do ministro Fernando Haddad (2005-2012), as políticas educacionais começam a tomar um rumo diferenciado na intenção de redimensionar a educação no governo Lula. O primeiro passo foi a criação do Plano de Desenvolvimento da Educação (Brasil, 2007b), que abrange programas voltados para a educação básica e a educação superior. 
No que diz respeito à educação inclusiva, o governo Lula, através do PDE, implementa um amplo programa com o propósito de transformar os sistemas de ensino, para o andamento das políticas de inclusão. Destaca-se, nesse plano, o programa da formação de professores para a educação especial, a implantação de salas de recursos multifuncionais, a acessibilidade arquitetônica e o acesso e a permanência das pessoas com deficiência na educação superior.

Em 2004, através do decreto no 5.296 (Brasil, 2004), o governo regulamentou as leis $n^{\circ} 10.048$ e $n^{\circ} 10.098$, que estabelecem normas e critérios para promoção da acessibilidade às pessoas com deficiência. $\mathrm{O}$ decreto no 5.626 (Brasil, 2005), que regulamentou a lei no 10.436 (Brasil, 2002), discorre, além de outras coisas, sobre a Libras como disciplina curricular nos cursos de formação de professores (Brasil, 2010).

No ano de 2006, a Conferência sobre os Direitos das Pessoas com Deficiência, aprovada pela ONU, diz que os Estados-partes devem assegurar um sistema de educação inclusiva em todos os níveis. Isso deve garantir que o Brasil, como país partícipe, venha seguir essa orientação. Como já afirmamos anteriormente, nesse mesmo ano é lançado o Plano Nacional de Educação em Direitos Humanos (Brasil, 2007a).

Em 2008, o Ministério da Educação (MEC) lança a Política Nacional de Educação Especial na Perspectiva da Educação Inclusiva. Esse documento traz os objetivos e as diretrizes que devem nortear a educação especial na perspectiva da inclusão e faz um breve levantamento dos marcos históricos e normativos conceituando a educação especial e seu público (Brasil, 2010).

O governo do presidente Lula cria programas de expansão do acesso ao ensino superior, como o Programa Universidade para Todos (Prouni) - que tem por finalidade a concessão de bolsas de estudo, tanto integrais quanto parciais, para estudantes de cursos de graduação e dos cursos sequenciais, em instituições privadas - e o Programa de Apoio a Planos de Reestruturação e Expansão das Universidades Federais (Reuni) - com vistas ao acesso às universidades públicas, assim como a garantia de permanência (Castro, 2011).

Dando sequência a expansão, o governo Lula apresenta outra proposta de modernização das universidades federais com o UAB (Universidade Aberta do Brasil), rede de educação à distância, com o enfoque na graduação em licenciatura de professores da educação básica. Outro instrumento da política de expansão se encontra no Plano Nacional de Assistência Estudantil (PNAES), que tem como objetivo dar apoio aos estudantes mais carentes como forma de garantir a permanência na universidade.

Essas e outras medidas vieram contribuir para a democratização do acesso ao ensino superior, visando principalmente atingir camadas anteriormente excluídas do sistema educacional. No entanto, compreendemos que as pessoas surdas ainda encontram muitas barreiras nesse processo de expansão e democratização do acesso ao ensino superior.

Educação \& Realidade, Porto Alegre, v. 43, n. 1, p. 255-273, jan./mar. 2018. 


\title{
Limites e Avanços das Políticas Educacionais de Inclusão e o Acesso do Surdo ao Ensino Superior
}

Nossa pesquisa está ancorada na abordagem qualitativa que traz a possibilidade de buscarmos a compreensão da realidade configurada pelo desenho complexo e dinâmico, no qual estão imbricadas diversas variáveis que não podem ser isoladas nem desvalorizadas, como, por exemplo, aspectos sociais, psicológicos, comportamentais e outros.

Na visão de Ludke e André (1986), o papel do pesquisador é o de servir como veículo inteligente e ativo na articulação entre o conhecimento acumulado e os novos, que podem surgir como resultado da pesquisa. Assim, na perspectiva da abordagem qualitativa, o pesquisador é parte do fenômeno que investiga, estabelecendo como campo de pesquisa uma inter-relação, excluindo dessa maneira a possibilidade de neutralidade.

No percurso metodológico, adotamos como princípio a proposta de metodologia interativa apresentada por Maria Oliveira (2010). Apresentamos a seguir o conceito dessa metodologia exposta pela autora:

\begin{abstract}
A metodologia interativa como sendo um processo hermenêutico-dialético que facilita entender e interpretar a fala e depoimentos dos atores sociais em seu contexto e analisar definições em textos, livros e documentos, em direção a uma visão sistêmica da temática em estudo (Oliveira, 2010, p. 123).
\end{abstract}

Como técnica de análise, utilizamos os pressupostos teóricos da análise de conteúdo com o objetivo de interpretar os discursos contidos na legislação e nas falas dos indivíduos envolvidos na pesquisa. Franco (2007) ressalta a crescente utilização da análise de conteúdo como ferramenta de interpretação no âmbito das pesquisas educacionais. $\mathrm{O}$ autor apresenta como ponto de partida da análise de conteúdo a mensagem, afirmando que pode ser verbal, gestual, silenciosa, figurativa ou documental. Ele esclarece ainda que a mensagem expressa um significado e um sentido, uma vez que existe uma relação direta entre as condições contextuais do emissor e a mensagem. Assim, afirma que "toda análise de conteúdo implica comparações contextuais" (Franco, 2007, p. 19; 20).

Dessa forma, para estabelecermos o diálogo entre os limites e os avanços que perpassam o processo seletivo de acesso ao ensino superior para as pessoas surdas, definimos como percurso metodológico o levantamento documental das políticas educacionais de inclusão, resultantes das conferências internacionais no âmbito das orientações educacionais e políticas. Tivemos ainda como campo de investigação o discurso de alunos surdos concluintes do ensino médio de uma Escola Estadual de Pernambuco.

O grupo de sujeitos está compreendido por oito estudantes surdos: 03 do sexo masculino e 05 do sexo feminino. No momento da pesquisa, encontravam-se em idade aproximada entre 17 a 25 anos. Todos 
em fase de conclusão do ensino médio e preparando-se para o vestibular de 2013. O critério de escolha dos participantes está no fato de serem concluintes do ensino médio, dando assim a possibilidade de termos uma amostragem significativa, no sentido de apresentar os resultados necessários a nossa investigação. Para resguardarmos a identidade dos sujeitos da pesquisa, os mesmos estarão aqui apresentados através de letras constantes do alfabeto, como A, B, C, D, E, F, G e H.

$\mathrm{O}$ instrumento utilizado foi o questionário, estruturado com questões fechadas e abertas. Como os sujeitos são do ensino médio, consideramos apropriado o uso da língua portuguesa, uma vez que teríamos a presença do intérprete para traduzir as questões. O propósito foi investigar quais as perspectivas dos estudantes surdos em relação ao ensino superior e quais possíveis dificuldades tendem a afastá-los do processo de seleção. O instrumento foi aplicado individualmente para cada sujeito, com a contribuição do profissional intérprete de língua de sinais, que traduziu o questionário para os alunos surdos e, consequentemente, contribuiu para a compreensão da resposta escrita de cada participante nas questões abertas.

Como sustentação teórica para a análise dos dados, sistematizamos nossos estudos em categorias teóricas. Nesse sentido, Maria Oliveira (2010), valendo-se de outros autores, define categoria como a palavra relacionada à classificação ou "agrupamento de elementos que são sistematizados pelo pesquisador (a) após a pesquisa de campo, ou durante a análise de conceitos em livros didáticos, textos e documentos" (Oliveira, 2010, p. 93).

Utilizando as premissas desse conceito, elegemos como categorias teóricas a educação dos surdos, os direitos linguísticos numa sociedade plurilíngue, o reconhecimento da identidade e da cultura surda e as políticas educacionais de inclusão no processo de democratização de acesso ao ensino superior. Assim, estabelecemos quatro unidades de análises, que foram constituídas por agrupamentos de questões. Os agrupamentos foram analisados à luz das categorias teóricas.

\section{Unidade 1: tipo de comunicação dos surdos}

Na primeira unidade, desenvolvemos nossas análises com base no tipo de comunicação utilizada pelos surdos e nas categorias teóricas que dissertam sobre os principais aspectos sociais e culturais que envolvem a língua de sinais. Todos os sujeitos envolvidos na pesquisa, que responderam ao questionário, são usuários da Libras, o que demonstra a afirmação dos direitos adquiridos após o período que marcou o surgimento das políticas linguísticas.

No entanto, Skliar (2012) menciona o fracasso escolar dos surdos, mesmo com o reconhecimento da língua de sinais, e questiona os projetos políticos, os direitos linguísticos e o processo de reorganização escolar, afirmando que esses não conseguem se aproximar da visão que são apresentados pelos estudos culturais, que trata da questão da surdez no âmbito da visão socioantropológica e cultural. 
Nesse sentido, percebemos que o bilinguismo surge como a proposta educacional mais próxima dessa compreensão sociolinguística da surdez e da língua de sinais. No entanto, sabemos que a organização do sistema escolar, numa perspectiva bilíngue, ainda não atende as necessidades linguísticas dos surdos. De acordo com Quadros (2011), a língua de sinais é coadjuvante no processo de ensino aprendizagem, e a mudança de status dessa língua depende da posição política e afirmativa das pessoas surdas em busca de um bilinguismo aditivo, ou seja, não devendo uma língua se sobrepor a outra. "Assim, a educação dos surdos na perspectiva bilíngue toma uma forma que transcende as questões puramente linguísticas. Para além da língua de sinais e do português, esta educação situa-se no contexto de garantia de acesso e permanência na escola" (QUADROS, 2011, p. 34).

\section{Unidade 2: perspectiva dos surdos quanto ao ensino superior}

Os argumentos teóricos que embasam esta unidade de análise estão ancorados no debate sobre as oportunidades oferecidas aos surdos e principalmente às políticas de inclusão.

Quanto às perspectivas dos entrevistados em relação ao ingresso ao ensino superior, os sujeitos A, C, E, F e G pretendem concorrer a uma vaga. No entanto, somente o sujeito A respondeu que o ensino médio o potencializa para enfrentar o processo seletivo.

Os sujeitos B e D responderam que não querem concorrer a vagas em uma universidade pública. Em conversa com o intérprete, os mesmos afirmaram ser o processo seletivo "muito forte, difícil". Dentre todos, apenas um manifestou o desejo de cursar uma faculdade particular.

Ao serem questionados sobre o interesse pelo curso de Letra/Libras, os sujeitos A, B e C não mostraram interesse. Os demais, correspondente à maioria, demonstraram interesse em cursar Letras/Libras, revelando a importância desse curso para os surdos e a educação de crianças surdas.

Ainda nessa mesma unidade de análise estão classificados pelo instrumento de pesquisa os cursos de interesse dos sujeitos pesquisados. Podemos perceber que mesmo com a identificação com o curso de Letras/Libras, todos os sujeitos revelam interesse por outras áreas como: Português, Filosofia, Economia, Fotografia, Design, Matemática, Gastronomia, Fisioterapia, Psicologia e áreas profissionais como Cabeleireiro e Policial investigador.

Constatamos, através dos dados do Censo de 2011, que o quantitativo de surdos inseridos no ensino superior é insignificante. As políticas públicas de acessibilidade, considerando todos os seus aspectos, ainda não estão garantindo efetivamente a ampliação desse acesso. $O$ decreto no 5.626 (Brasil, 2005), que dispõe de um planejamento linguístico assegurando a importância sociocultural e cognitiva para a aprendizagem e afirmação política da pessoa surda, também não atingiu suas metas 
de formação de professor, instrutor e tradutor/intérprete de Libras, que poderiam oportunizar o aumento do quantitativo de pessoas surdas no ensino superior.

Entendemos que a língua se estabelece como um dos limites para a participação da pessoa surda no processo seletivo, uma vez que o exame se dá na língua portuguesa.

\section{Unidade 3: proposta pedagógica e a preparação para o processo seletivo}

Definimos como terceira unidade de análise a proposta pedagógica e a preparação para o processo seletivo, tendo como suporte teórico as propostas educacionais e o bilinguismo na educação dos surdos, considerando as políticas de inclusão.

Como já foi dito, ao serem questionados se o conhecimento do ensino médio potencializa o estudante surdo para enfrentar o processo seletivo, apenas um dos entrevistados respondeu positivamente, afirmando ser o estudo do ensino médio capaz de potencializá-lo para enfrentar o processo seletivo. Os demais sujeitos dizem não estar preparados para o processo de seleção à universidade pública.

Quanto à trajetória escolar, os sujeitos C, D, E, F, G e H afirmaram ter tido em sua formação, nos anos iniciais do ensino fundamental, professores bilíngues e, nos anos finais, ter contado com a presença do professor e do intérprete. Os sujeitos A e B responderam que em todo o ensino fundamental a formação ocorreu com o professor e o interprete. Entendamos que nesse contexto o professor bilíngue é aquele que tem o domínio da língua de sinais e do português, mas isso não é indicativo de que a proposta educacional seja necessariamente uma proposta educacional bilíngue.

Quanto às propostas pedagógicas dirigidas à educação dos surdos, nossos dados nos revelaram que existe o predomínio de uma língua sobre a outra, ou seja, a língua portuguesa como a língua mais importante no processo, tendo a Libras como suporte para o acesso à informação através do intérprete. Nesse aspecto, Skliar (2012) problematiza a questão na ordem das representações que permeiam o modelo clínico e o modelo baseado nos estudos culturais. Ele diz que ambos estão dominados pelos preceitos hegemônicos da relação de poder, imposta por uma maioria denominada por ele como "maioria ouvinte".

Na concepção sobre a educação dos surdos, como vimos, perpassa sempre a valorização da Língua Portuguesa como primeira língua para as pessoas surdas. Isso mostrou que mesmo com as políticas linguísticas, a realidade esbarra na compreensão que se tem sobre a surdez e o surdo. Essa proposta não se configura como eficaz devido à negação do discurso sobre a educação que os surdos querem. De acordo com Goldfeld (2002), há uma inclinação na perspectiva da diferença sobre a questão da surdez, embora ainda prevaleça o propósito da aprendizagem da língua oral auditiva.

Educação \& Realidade, Porto Alegre, v. 43, n. 1, p. 255-273, jan./mar. 2018. 
Para que o processo de ensino e aprendizagem dos surdos possa se dar numa perspectiva bilíngue, Quadros (2008) apresenta em seus estudos a importância de se definir diretrizes efetivas para a constituição de uma escola bilíngue, que realmente tenha a Libras como língua de instrução dos surdos e a língua portuguesa como segunda língua.

Acrescentamos que a escola lócus dessa pesquisa não se configura como escola bilíngue, e sim como uma escola com proposta inclusiva com intérpretes atuando junto aos professores e com a sala de atendimento educacional especializado. Mas, que mantém a língua portuguesa no status de primeira língua, ou seja, educação para pessoas surdas pensadas por ouvintes com a estrutura de ensino para ouvintes.

\section{Unidade 4: limites quanto ao acesso ao ensino superior}

A quarta unidade de análise estabelecida em nosso trabalho se apresenta com base no limite quanto ao acesso ao ensino superior. Tivemos como suporte teórico para essa discussão as políticas educacionais, as políticas linguísticas e as políticas de acessibilidade.

Quanto ao que dificulta a aprovação no vestibular, os sujeitos A, G e $\mathrm{H}$ disseram que falta tradução da prova para a língua de sinais. Mas, de acordo com o decreto 5.296 (Brasil 2004), que trata sobre acessibilidade, e do aviso circular no 277 (Brasil, 1996b), do Ministério da Educação, que versa sobre a presença do intérprete no processo seletivo, o surdo tem direito ao intérprete, porém não implica que esse intérprete possa traduzir a prova. Esse procedimento incorreria em questões éticas, caso fosse dado ao intérprete a atribuição de traduzir todo o conteúdo da prova. Portanto, a participação do intérprete se restringe a tradução dos informes principais, o que não garante condições equitativas no processo seletivo. Os sujeitos C, F, G e H também apontaram a língua portuguesa como um entrave no processo seletivo para o ingresso ao ensino superior.

Posto que o ensino médio não os potencializa, ficou evidente que o pouco conhecimento também os impossibilita de competir em condições de igualdade. Os sujeitos B, C, D, E, e F confirmaram não possuir conhecimento suficiente como fator que poderá dificultar a aprovação no processo seletivo. E aí cabe uma questão, qual o porquê da defasagem na educação desses sujeitos, além do mesmo motivo que afetam os outros estudantes?

Com base nesses dados, podemos inferir que, além do pouco conhecimento conteudista, a língua portuguesa configura-se também como um entrave para os surdos no processo seletivo. Considerando que, mesmo que estivessem em condições iguais quanto aos conhecimentos e competências necessárias para alcançar o índice de aprovação, ainda assim poderiam esbarrar na língua portuguesa, uma vez que essa língua é para os surdos a segunda língua.

Ao serem indagados sobre o que falta para chegar ao ensino superior, os sujeitos da pesquisa disseram que:

268 Educação \& Realidade, Porto Alegre, v. 43, n. 1, p. 255-273, jan./mar. 2018. 
A - Eu falta futuro precisa curso vestibular português. Eu também quero governo (sic).

$\mathrm{B}$ - Você fazer não falta não falta vestibular (sic).

$\mathrm{C}$ - Eu gosto muito de estudando (sic).

D - Eu quero vontade pessoa faculdade curso aprender sinho futuro (sic).

E - Eu sempre estudo UPE UFPE interesse (sic).

F - Eu quero só de especial são surdos (sic).

G - Só intérprete (sic)

$\mathrm{H}$ - Intérprete (sic).

Ao analisar a questão, destacamos as argumentações por eles apresentadas, fazendo as devidas traduções com a contribuição do intérprete.

O sujeito A disse que, para chegar ao ensino superior, o governo precisa organizar ou implementar cursos pré-vestibulares de português. O sujeito B, sendo coerente com seu discurso em todo questionário, afirma que não quer fazer o vestibular. Quanto ao C, considerando o fato de que gosta de estudar e suas respostas em todo questionário, podemos inferir que, com estudos, será possível chegar à universidade. O sujeito D manifesta seu desejo de fazer um curso em uma faculdade e tem isso como um sonho para seu futuro. Percebemos que os sujeitos buscam em si mesmo um atributo que possa conduzi-los com êxito no ingresso ao ensino superior.

O sujeito E declarou seu interesse em estudar em duas universidades públicas do Estado de Pernambuco - a Universidade de Pernambuco (UPE) e Universidade Federal de Pernambuco (UFPE). O sujeito F manifestou o desejo por uma escola especial para surdos como o meio, possivelmente mais adequado, de se chegar ao ensino superior. Os sujeitos $\mathrm{G}$ e $\mathrm{H}$ responderam que faltam intérpretes, entenda-se, nos exames seletivos. O que provavelmente eles não compreendem é que não é possível a interpretação da prova na íntegra, mas o direito garantido apenas como acessibilidade comunicacional na hora da realização do exame, ou seja, para a interpretação dos informes e não da prova em si.

Observamos que dos oito sujeitos, quatro apontaram para fatores externos. Consideram que as soluções para viabilizar um processo de ingresso de forma mais equitativa estão no âmbito das políticas públicas e que as condições necessárias para chegar ao ensino superior não estão apenas em suas potencialidades.

Os sujeitos A, F, G e H apontaram para soluções que estão na esfera governamental ou implicadas nas políticas públicas e educacionais. Inferimos que o sujeito A, ao citar o governo em sua fala, reivindicou por uma atenção quanto à preparação desses alunos para enfrentar o processo seletivo, principalmente considerando a preocupação dos mesmos com a língua portuguesa. Já C, D e E tomaram para si o desejo de estudar, e E destacou as universidades públicas como interesse de realização dos seus estudos. Assim, inferimos que essa é mais uma solicitação pelos direitos a uma educação pública.

Nesse sentido, retomamos os valores prescritos no PNEDH, que diz que o estado brasileiro deve efetivar políticas públicas no sentido 
de considerar os princípios dos direitos humanos, afirmando o compromisso pela promoção da igualdade de oportunidades e da equidade. Destacamos que o PNEDH tem como alguns dos seus princípios, quanto ao ensino superior, o de garantir a democratização à informação, o acesso dos grupos vulneráveis e excluídos e, principalmente, a implementação de políticas públicas que atendam necessidades básicas desses segmentos sociais excluídos. Consideremos então uma questão não só de pessoas com deficiências, mas todo espectro de excluídos da sociedade, inclusive os considerados de minoria linguística.

Ao serem indagados sobre o que os impede de tentar fazer o vestibular para uma universidade pública, os sujeitos da pesquisa responderam que:

A - Eu cá vou entre cá barreira sempre faculdade ou Eu cá não entre barreira hora coisa marca pessoa Eu só vida que futura sonho. Eu futuro vida cá vontade. Eu agora não ainda só futuro pensar, ok (sic).

$\mathrm{B}$ - Eu como difícil muito, mas não vestibular (sic).

C - Claro que sim (sic). Observação: não concluiu resposta.

$\mathrm{D}$ - Que importante bom, mas governador voltar não difícil Eu quer falar governador (sic).

E - Eu espera derma hoja Enem (sic).

F - São dificuldades da estudar as coisas (sic).

G - não entender (sic).

O sujeito A tomou para si o motivo que o impede de fazer o exame seletivo. O sujeito B manteve o discurso de não querer fazer faculdade ou curso superior. O sujeito C compreendeu que a pergunta é se vai tentar o vestibular em universidade pública, e sua resposta teve caráter afirmativo. O sujeito D expressou o anseio em tratar com o governo sobre seus direitos. O sujeito E aguardou o Enem para se submeter ao processo seletivo. O sujeito $\mathrm{F}$ atribuiu a si mesmo os motivos que o impedem de fazer o vestibular em uma universidade pública. Quanto ao sujeito $\mathrm{G}$, disse não ter entendido a pergunta, e o sujeito H não respondeu.

Acrescentamos que, dos sujeitos envolvidos na pesquisa, apenas um está atualmente cursando o nível superior em uma faculdade particular, os demais fizeram o exame no Enem, mas não passaram.

Percebemos que os anseios declarados pelos sujeitos da pesquisa se pautaram nos discursos da equidade. É nesse sentido que as políticas de inclusão precisam encontrar o equilíbrio entre o que preceitua e o que prescreve nas políticas linguísticas voltadas para a educação dos surdos.

\section{Considerações Finais}

Como podemos acompanhar no corpo teórico deste trabalho, apesar das políticas de expansão e democratização do acesso ao ensino superior, são raras as oportunidades oferecidas aos surdos que atendam suas especificidades linguísticas. 
Compreendemos que as políticas direcionadas às pessoas com deficiência são as políticas de inclusão representadas em seus desdobramentos no que diz respeito à acessibilidade em todos os seus aspectos. Aos surdos, ainda destinam-se os direitos linguísticos. E a Universidade Aberta do Brasil com o curso de Letras/Libras tem se concretizado, de fato, como um dos poucos meios de acesso ao ensino superior para as pessoas surdas, pela identidade cultural que representa para os surdos. Porém, a barreira que se apresenta precisa ser superada, e esta se constitui no processo seletivo, pois o surdo precisa lidar com a língua portuguesa como primeira língua.

Como citamos antes, a educação bilíngue é um desafio, mas deve estar a cargo de uma política nacional centrada nos aspectos que definem as especificidades linguísticas, culturais, políticas e sociais da comunidade surda. Embora essa proposta já se constitua como política educacional, é necessário que seja discutida profundamente nos campos científico, político e social, redimensionando caminhos efetivamente eficazes. É necessário ainda que ela não seja apenas um desafio para professores e alunos, mas um desafio da política educacional nacional, considerando, portanto, as especificidades do ensino e da aprendizagem da pessoa surda.

Com base nessa argumentação, relembramos Goldfeld (2002), que afirma ser a língua de sinais a única língua que o surdo pode dominar com êxito, servindo a todas as suas necessidades comunicacionais e também cognitivas. Essas premissas fortalecem $a$ priori a necessidade de se aprofundar um estudo sobre a implementação urgente de escolas bilíngues, onde, de fato, a língua de sinais seja considerada a língua de instrução dos estudantes surdos. Essas prerrogativas podem dar condições reais de possibilidades para que a pessoa surda tenha acesso a todos os níveis de ensino e também de aprendizagem.

Por isso, a mobilização por parte desses grupos se faz urgente na perspectiva de alcançar a educação como bem público. A universidade precisa estar disposta a ouvir o surdo e a atender suas necessidades mais específicas, não só para o ingresso, no sentido de repensar o processo seletivo, mas principalmente pela permanência desse estudante na academia, garantindo a esses grupos excluídos o conhecimento institucionalizado.

Recebido em 08 de abril de 2016 Aprovado em 19 de abril de 2017

\section{Notas}

1 Congresso Internacional de Educadores de Surdos, realizado em Milão em 1880. Alexander Graham Bell teve grande influencia na votação que elegeu o Oralismo, como melhor método de ensino para os surdos (Goldfeld, 2002). 


\section{Referências}

BRASIL. Lei no 9.394, de 20 de dezembro de 1996. Lei de Diretrizes e Bases da Educação Nacional. Estabelece as diretrizes e bases da educação nacional. Diário Oficial [da República Federativa do Brasil], Brasília, DF, v. 134, n. 248, 23 dez. 1996a. Seção I. P. 27834-27841.

BRASIL. Ministério da Educação. Secretaria de Educação Continuada, Alfabetização, Diversidade e Inclusão. Aviso Circular no 277, de 08 de maio de 1996. Brasília, DF, 1996b. Disponível em: <http://portal.mec.gov.br/seesp/arquivos/ pdf/aviso277.pdf>. Acesso em: 27 mar. 2012.

BRASIL. Conselho Nacional de Educação. Ministério da Educação. Resolução CNE/CEB no 2, de 11 de setembro de 2001. Institui Diretrizes Nacionais para a Educação Especial na Educação Básica, Brasília, DF, 2001.

BRASIL. Lei 10.436, de 24 de abril de 2002. Dispõe sobre a Língua Brasileira de Sinais - Libras e dá outras providências. Diário Oficial da União, Presidência da República, Brasília, DF, 2002.

BRASIL. Decreto no 5.296 de 02 de dezembro de 2004. Regulamenta as Leis no 10.048 , de 8 de novembro de 2000, que dá prioridade de atendimento às pessoas que especifica e 10.098, de 19 de dezembro de 2000. Diário Oficial da União, Presidência da República. Brasília, DF, 2004.

BRASIL. Decreto no 5.626 , de 22 de dezembro de 2005. Regulamenta a Lei ${ }^{\circ}$ 10.436, de 24 de abril de 2002, que dispõe sobre a Língua Brasileira de Sinais, e o art. 18 da Lei no 10.098, de 19 de dezembro de 2000. Diário Oficial [da República Federativa do Brasil], Brasília, DF, 03 dez. 2005. Seção I. P. 28.

BRASIL. Plano Nacional de Educação em Direitos Humanos. Brasília: Secretaria Especial dos Direitos Humanos; Ministério da Educação; Ministério da Justiça; UNESCO, 2007a.

BRASIL. Plano de Desenvolvimento da Educação. Brasília: Ministério da Educação, 2007b.

BRASIL. Marcos Político-Legais da Educação Especial na Perspectiva da Educação Inclusiva. Brasília: Ministério da Educação; Secretaria de Educação Especial, 2010.

BRASIL. Relatório sobre a Política Linguística de Educação Bilíngue: língua brasileira de sinais e língua portuguesa. Grupo de Trabalho, designado pelas portarias no 1.060/2013 e nº 91/2013, Brasília, DF, 2014.

BRITO, Lucinda Ferreira. Por uma Gramática de Língua de Sinais. Rio de Janeiro: Tempo Brasileiro, 1995.

CARNEIRO, Moaci Alves. O Acesso de Alunos com Deficiência às Escolas e Classes Comuns: possibilidades e limitações. Petrópolis: Vozes, 2007.

CASTRO, Alda Maria Duarte Araujo. A Expansão e o Acesso ao Ensino Superior: os novos desafios da educação brasileira. In: SOUZA JUNIOR, Luiz de; FRANÇA, Magna; FARIAS Maria da Salete Barbosa de (Org.). Políticas de Gestão e Práticas Educativas: a qualidade do ensino. Brasília: Liber Livro, 2011. P. 19-36.

CUNHA, Luiz Antônio. O ensino superior no octênio FHC. Educação e Sociedade, Campinas, v. 24, n. 82, p. 37-61, abr. 2003. Disponível em: <http://www. cedes.unicamp.br>. Acesso em: 16 jan. 2012.

FELIPE, Tanya A. Libras em Contexto: curso básico, livro do estudante cursista. Brasília: Programa Nacional de Apoio à Educação dos Surdos, Ministério da Educação, 2001.

272 Educação \& Realidade, Porto Alegre, v. 43, n. 1, p. 255-273, jan./mar. 2018. 
FRANCO, Maria Laura Publisi Barbosa. Análise de Conteúdo. Brasília: Liber Livro, 2007.

GÓES, Maria Cecília Rafael de. Linguagem, Surdez e Educação. São Paulo: Autores Associados, 2002.

GOLDFELD, Marcia. A Criança Surda: linguagem e cognição numa perspectiva sociointeracionista. São Paulo: Plexus, 2002.

LÜDKE, Menga; ANDRÉ, Marli. Pesquisa em Educação: abordagens qualitativas. São Paulo: EPU, 1986.

OLIVEIRA, Dalila Andrade. Das Políticas de Governo à Política de Estado: reflexões sobre a atual agenda educacional brasileira. Educação e Sociedade, Campinas, v. 32, n. 115, p. 323-337, 2011. Disponível em: <http://www.scielo.br/pdf/ es/v32n115/v32n115a05.pdf>. Acesso em: 30 maio 2013.

OLIVEIRA, Maria Marly de. Como Fazer Pesquisa Qualitativa. Rio de Janeiro: Vozes 2010.

QUADROS, Ronice Müller de. Educação de Surdos: a aquisição da linguagem. Porto Alegre: Artmed, 2008.

QUADROS, Ronice Müller de. O ‘BI’ em Bilinguismo na Educação de Surdos. In: FERNANDES, Eulalia. In FERNANDES, Eulalia. (Org.). Surdez e Bilinguismo. Porto Alegre: Mediação, 2011. P. 27-37.

QUADROS, Ronice Muller; CAMPELLO, Ana Regina e Souza. A Constituição Política, Social e Cultural da Língua Brasileira de Sinais - LIBRAS. In: VIEIRA-MACHADO, Lucyenne Matos da Costa; LOPES, Maura Corcini (Org.). Educação de Surdos: políticas, língua de sinais, comunidade e cultura surda. Santa Cruz do Sul: EDUNISC, 2010. P. 15-47.

QUADROS, Ronice Müller de; KARNOPP, Lodenir Becker. Língua de Sinais Brasileira. Porto Alegre: Artmed, 2009.

SANTIAGO, Sandra Alves da Silva. A História da Exclusão da Pessoa com Deficiência: aspectos socioeconômicos, religiosos e educacionais. João Pessoa: Editora Universitária da UFPB, 2011.

SKLIAR, Carlos. Os Estudos Surdos em Educação: problematizando a normalidade. In: SKLIAR, Carlos (Org.). A Surdez: um olhar sobre as diferenças. Porto Alegre: Mediação, 2012. P. 7-32.

SOUZA JUNIOR, Luiz de. Política de Democratização do Acesso ao Ensino Superior. In: SOUZA JUNIOR, Luiz de; FRANÇA, Magna; FARIAS, Maria da Salete Barbosa de (Org.). Políticas de Gestão e Práticas Educativas: a qualidade do ensino. Brasília: Liber Livro, 2011. P. 37-56.

UNESCO. Declaração de Salamanca sobre Princípios, Política e Práticas na Área das Necessidades Educativas Especiais. Organização das Nações Unidas para a Educação, a Ciência e a Cultura, 1994. Disponível em: <http://unesdoc. unesco.org/images/0013/001393/139394por.pdf>. Acesso em: 30 mar. 2012.

Leila Santos Mesquita é professora da Secretaria de Educação de Pernambuco em regime de cedência à Universidade de Pernambuco, atuando com o ensino da disciplina de Educação Inclusiva e Libras. Professora do ensino fundamental na educação bilíngue para surdos e no Atendimento Educacional Especializado de estudantes inclusos no ensino regular.

E-mail: leylasmesquita@yahoo.com.br 